Journal of

Case Reports: Open Access

\title{
Early onset meningitis due to Morganella morganii: a case report
}

Valérie Tratsaert ${ }^{1,2}$, Verroken Alexia ${ }^{3}$, Diane Stroobant ${ }^{2,4}$, Aude Helsmoortel ${ }^{1}$, Anne Charon ${ }^{1}$, Dimitri Van der Linden ${ }^{2-5, *}$

${ }^{1}$ Neonatology, GHDC Charleroi, Belgium

${ }^{2}$ Pediatric Infectious Diseases, General Pediatrics, Pediatric Department, Cliniques universitaires Saint-Luc, Brussels, Belgium ${ }^{3}$ Microbiology Department, Cliniques universitaires Saint-Luc, Brussels, Belgium

${ }^{4}$ Pediatrics, Pediatric Department, GHDC Charleroi, Belgium

${ }^{5}$ Institut de Recherche Expérimentale et Clinique, UCLouvain, Brussels, Belgium

${ }^{*}$ Corresponding author: Dimitri Van der Linden, Pediatric Infectious Diseases, General Pediatrics, Pediatric Department, Cliniques universitaires Saint-Luc, Brussels, Belgium dimitri.vanderlinden@uclouvain.be

Received Date: March 11, 2019 Accepted Date: April 28, 2019 Published Date: April 30, 2019

Citation: Valérie Tratsaert (2019) Early onset meningitis due to Morganella morganii: a case report. Case Reports: Open Access 4: $1-4$.

\section{Summary}

We describe a case of a term newborn who developed Morganella morganii meningitis. M. morganii is a rare perinatal pathogen causing neonatal sepsis and chorioamnionitis. Prompt management of chorioamnionitis and prevention of early neonatal infection are imperative to reduce morbidity and mortality in both newborn and mother.

Keywords: Morganella morganii; Neonatal sepsis; Meningitis

(C)2019 The Authors. Published by the JScholar under the terms of the Creative Commons Attribution License http://creativecommons.org/licenses/ by/3.0/, which permits unrestricted use, provided the original author and source are credited. 


\section{Introduction}

Reports of central nervous system (CNS) infections due to Morganella morganii are scarce with only some cases reported in the literature $[1,2,12,15,24,33,35]$. M. morganii in newborns is an opportunistic pathogen which can cause neonatal infections and sepsis.

The presence of a chromosomally encoded inducible $\operatorname{ampC} \beta$-lactamase challenges the clinician in the selection of a targeted treatment and repeated microbiological cultures are mandatory in patient's follow-up $[3,10,32]$. Several reports describe severe neurologic sequelae or fatal outcome in neonates suffering from $M$. morganii meningitis or bacteremia due to delay of appropriate treatment $[8,23]$.

We discuss a case of a term newborn with early onset meningitis due to $M$. morganii successfully treated with a third-generation cephalosporin associated with an aminoglycoside.

\section{Case report}

After a rapid labor, a term female baby was born to a 32-year-old mother by spontaneous vaginal delivery. Rupture of membranes occurred 8 hours before delivery with malodorous amniotic fluid. The mother was afebrile during both labor and delivery and C-reactive protein (CRP) was negative. The pregnancy had been uneventful and group B Streptococcus (GBS) vaginal screening was negative. The mother didn't receive any antibiotics during pregnancy neither before delivery.

Physical examination at birth showed transient respiratory distress but 3 hours later the patient presented with a severe apnea requiring her admission to the neonatal intensive care unit. CRP was slightly elevated at $23 \mathrm{mg} / \mathrm{L}$. Chest X-ray was normal. Empirical antibiotherapy was initiated including ampicillin $100 \mathrm{mg} / \mathrm{kg} /$ day and amikacin $15 \mathrm{mg} / \mathrm{kg} /$ day. After 26 hours, the newborn presented irritability and a lumbar puncture was performed. Cerebral spinal fluid microscopy (CSF) showed 1760 white blood cells $/ \mathrm{mm}^{3}$ with neutrophilic pleiocytosis, decreased glycorrachia $(34 \mathrm{mg} / \mathrm{dL})$ and increased protein level $(1.90 \mathrm{~g} / \mathrm{L})$.

Ampicillin was switched to cefotaxime $(25 \mathrm{mg} / \mathrm{kg}$ every 6 hours for 21 days). A blood test was repeated 18 hours later and showed thrombocytopenia and increased CRP at $146 \mathrm{mg} / \mathrm{L}$. CSF culture grew for M. morganii Manual antimicrobial susceptibility testing with disks performed according to the CLSI 2017 guidelines showed susceptibility to cefotaxime, ceftazidime, cefepime, piperacillin/tazobactam, meropenem, aztreonam, amikacin, ciprofloxacin and trimethoprim/sulfamethoxazole.

Susceptibility to cefotaxime was alternatively confirmed with a minimal inhibition concentration (MIC) value of $0,094 \mu \mathrm{g} / \mathrm{ml}$. Three blood cultures remained sterile. Urine culture was also sterile. Surface swabs from the ear grew for the same strain. No placenta culture was performed.

Her clinical condition improved after 24 hours of treatment and CRP declined steadily. Repeated CSF sample performed 9 days after the initiation of the antibiotics was sterile and subsequent brain imaging (RMN and ultrasound) was normal.

\section{Discussion}

M. morganii is a gram-negative facultative anaerobe rod commonly found in the environment and in the intestinal tract of humans (as part of the substitution flora), mammals, and reptiles [25,35]. It is an uncommon cause of community-acquired infection and is most often found in adult nosocomial infections such as urinary tract infections [32], hepatobiliary tract and surgical wound infections $[21,23,24,27]$. Necrotizing fasciitis, pericarditis [31], septic arthritis and endophthalmitis [13] have been rarely reported.

Early onset $M$. morganii neonatal sepsis is rare but may cause serious invasive disease. The clinical signs are non-specific, but the most common symptoms are respiratory distress and tachypnea. There is no sex predilection [8] but this infection mostly affects premature babies $[28,29,30]$. The mortality and morbidity rates are even higher in lower gestational and smaller birth weight preterm infants.

The most common antenatal risk is maternal chorioamnionitis $[6,7,15,18,22]$ but also the use of antibiotics before delivery [29]. It is suggested that the use of intrapartum ampicillin prophylaxis for group $\beta$-streptococcal infection is a risk factor for the natural selection of M. morganii strains [32]. For this reason, $M$. morganii should be considered, despite its rarity, as a potential pathogen in sepsis caused by vertical transmission $[5,32]$.

M. morganii has an inducible $\operatorname{amp} C \beta$-lactamase which initially confers resistance to certain narrow spectrum $\beta$-lactam antibiotics (e.g. penicillins, first- and second-generation cephalosporins) [20,23,25,27,33]. Moreover, the over-production of the enzyme can ultimately lead to third-generation cephalosporin resistance explained by a reversible inducible expression or a de-repressed constitutive expression of the $\operatorname{ampC}$ gene. Various 
$\beta$-lactams including third-generation cephalosporins are considered as inducers of this $a m p C$ expression mechanism. However, evidence is still lacking on the frequency of mutation towards constitutive resistance $[3,15,25,33]$. To prevent this phenomenon, confirmed M. morganii sepsis should be treated with a combination of third-generation cephalosporin and aminoglycoside. $[19,22,29]$.

\section{Conclusion}

M. morganii is a rare cause of neonatal sepsis and meningitis. Knowing its extended resistances profile, appropriate antibiotics should be initiated as soon after bacteriological identification. Genome sequencing of $M$. morganii could further provide important information concerning virulence and determinants of fitness.

\section{References}

1. Abdalla J, Saad M, Samnani I, Lee P, Moorman J (2006) Central nervous system infection caused by Morganella morganii. American Journal of the Medical Sciences 331:44-47.

2. Auvichayapat N, Auvichayapat P, Aungwarawong S (2007) Brain abscess in Infants and Children: A retrospective study of 107 patients in Northeast Thailand. Journal of the Medical Association of Thailand 90:1601-1607.

3. Barnaud G, Arlet G, Danglot C, Philippon A (1997) Cloning and sequencing of the gene encoding the ampC $\beta$-lactamase of Morganellamorganii. Microbiology Letters 148:15-20.

4. Barroso H, Freitas-Vieira A, Duarte A (1999) Molecular Characterization of a Ceftazidime-Resistant Morganella morganii Isolate Producing a TEM-10 $\beta$-lactamase. Antimicrobial Agents and Chemotherapy 43:434-435.

5. Boussemart T, Piet-Duroux S, Manouana M, Azi M,et al. (2004) Morganella morganii and early-onset neonatal infection. Archives de pédiatrie 11: 37-39.

6. Carmona F, Fabregues F, Alverez R, Vila J, Cararach V (1992) A rare case of chorioamniotis by Morganellamorganiicomplicated by septicemia and adult respiratory distress syndrome. European Journal of Obstetrics and Gynecology and Reproductive Biology 45:67-70.

7. Casanova-Roman M, Sanchez-Porto A, Casanova-Bellido M (2002) Early-onset Neonatal Sepsis Caused by Vertical transmission of Morganellamorganii. Scandinavian Journal of Infectious Diseases. 34:534-551.

8. Chang HY, Wang SM, Nan-Chang Chiu, Chung HY, et al. (2011) Neonatal Morganella morganii sepsis : a case report and review of the literature. Pediatrics International 121-123.

9. Chen HW, Lin TY (2011) Tumor abscess formation caused by Morganella morganii complicated with bacteremia in a patient with gastrointestinal stromal tumor. Clinics and Research in Hepatology and Gastroenterology 14.

10. Chen et al. (2012) Whole-genome sequencing and identification of Morganellamorganii KT pathogenicity-related genes. BMC Genomics. 13(supplement 7): S4.

11. Choi SH, Lee JE, Park SJ, et al. (2008) Emergence of antibiotic resistance during therapy for infections caused by Enterobacteriaceae producing ampC $\beta$-lactamase: implications for antibiotic use. Antimicrobial Agents and Chemotherapy 52: 995-1000.

12. Chuang YC, Chang W, Huang CR, Chen H (1998) Morganella morganiicentran Nervous System Infection: Case report and review. Infectious Disease in Clinical Practice 8:5052.

13. (2017) Committee Obstetric Practice. Intrapartum Management of intraamniotic infection. Committee Opinion No.712. Obstetrics and Gynecology 130: 95-101.

14. Demiray T, Aydemir O.A, Koroglu M, Ozbek A, et al. (2016) severe Morganella morganii endophthalmitis; followed by bacteremia. Iran Journal of Microbiology 8:70-72.

15. Dutta S, Narang A (2004) Early-onset neonatal sepsis due to Morganellamorganii. Indian Pediatrics, 41:1155-1157.

16. Harris PNA, Ferguson JK (2012) Antibiotic therapy for inducible ampC $\beta$-lactamase-producing Gram-negative bacilli: what are the alternatives to carbapenems, quinolones, and aminoglycosides? International Journal of Antimicrobial Agents 40: 297-305.

17. Jacoby G (2009) ampC $\beta$-lactamases. Clinical Microbiology Reviews 161-182.

18. Johnson JR, Feingold M (1998) Case of chorioamnio- 
nitis in an immunocompetent woman caused byMorganellamorganii. Journal ofMaternal-FetalMedicine 7:13-14.

19. Jones, Baquero F, Privitera G, Inoue M, et al. (1997) Inducible $\beta$-lactamase-mediated resistance to third-generation cephalosporins. Clinical Microbiology and Infection. 3 Supplement.

20. Karen M, Puopolo MD, et al. (2010) No change in the incidence of Ampicillin-Resistant, neonatal, early-onset sepsis avec 18 years. Pediatrics. 125:5.

21. Lin TY, Chan MC, Yang YS, Lee Y, Yeh KM, et al. (2015) Clinical manifestations and prognostic factors of Morganellamorganii.European Journal of Clinical Microbiology and Infectious Disease. 34:231-236.

22. Lee I-K, Liu J-W (2006) Clinical characteristics and risk factors for mortality in Morganellamorganiibacteremia. Microbiology Immunology Infection 39:328-334.

23. Liu H, Zhu J, Hu Q, Rao X (2016) Morganella morganii, a non-negligent opportunistic pathogen. International journal of infectious diseases.

24. Milligan, K. l. and Stephen J. Barenkamp (2012) Neonatal meningitis de to to Morganella morganii.Clinical Pediatrics 52: $462-464$.

25. Nakazawa T, Obinata K, Nagata Y, Ebara K, Suzuki K, et al. (2013) A case of Morganella morganii Meningoencephalitis. Journal of Infectious Disease 1:118.

26. Ndiaye M, Sène MS, Sow AD, Seck LB (2010) Coulibaly T, Diagne NS, Touré K, Diop AG. Meningoencephalitis due to Morganella morganii : a case report. Bulletin de la Société de Pathologie Exotique 103: 230-232.

27. O'Hara C, Brenner F, Miller M (2000) Classification, identification, and clinical significance of Proteus, Providencia and Morganella. Clinical Microbiology Reviews 13: 534-546.

28. Ranu SS, Valencia GB, Piecuch S (1999) Fatal earlyonset infection in an extremely low birth weight infant due to Morganellamorganii. Journal of Perinatology 19:533-535.

29. Rowen JL, Lopez SM (1998) Morganella morganii early-onset sepsis. Pediatric Infectious Disease Journal 17:11761177.
30. Salen PN, Eppes S (1997) Morganella morganii: a newly reported, a rare cause of neonatal sepsis. Academic Emergency Medicine 4:711-714.

31. Samonis G, Anatoliotaki M, Apostolakou H, et al. (2001) Fatal septicemia and meningitis due to Morganellamorganii in a patient with Hodgkin's disease. Journal of Infectious Diseases 33:553-555.

32. Sinha A.K, Kempley S, Price E, Sharma B, Livermore D (2006) Early onset Morganellamorganii sepsis in a newborn infant with the emergence of cephalosporine resistance caused by derepression of AmpC $\beta$-lactamase production. The Pediatric Infectious Disease Journal.

33. Stock Ingo and Wiedemann Bernd (1998) Identification and natural antibiotic susceptibility of Morganellamorganii. Diagnostic microbiology infection disease 30:153-165.

34. Thomas VA, Satish Kumar T, Agarwal I, Chacko AG (2007) An unusual cause of brain abscess in an infant. Journal of Pediatric Neurosciences 2:94.

35. Trivedi MK, Branton A, Trivedi D, Nayak G, Gangwar M, et al. (2015) Antibiogram and genotypic Analysis using 16S rDNA after Biofield Treatment on Morganellamorganii. AdvancedTechniques inBiologyandmedicine 3:3.

36. Verboon-Maciolek M, Vandertop WP, Peters AC, et al. (1995) Neonatal brain abscess caused by Morganella morganii. Clinical infectious Diseases 20: 471.

Submit your manuscript to a JScholar journal and benefit from:

q Convenient online submission

I Rigorous peer review

9 Immediate publication on acceptance

T Open access: articles freely available online

I. High visibility within the field

ๆ Better discount for your subsequent articles

Submit your manuscript at http://www.jscholaronline.org/submit-manuscript.php 